\title{
TEXT COMPLEXITY IN SENIOR HIGH SCHOOL ENGLISH TEXTBOOKS, A SYSTEMIC FUNCTIONAL PERSPECTIVE
}

\author{
Dhani Aldila Putra \\ Iwa Lukmana \\ Universitas Pendidikan Indonesia \\ dhaditra@gmail.com; iwa.di.bandung@gmail.com
}

First received: 27 February 2017

Final proof received: 28 September 2017

\begin{abstract}
Textbooks have been considered to play a key role in the processes of education by researchers and educators, and the need to explore the language of textbooks has become increasingly recognized. However, although textbooks are an important learning tool, textbook language and composition have not been widely explored especially from textual perspectives. The purpose of the present study is to investigate text complexity progression in the reading texts of English textbooks published for senior high school students in Indonesia. The nature and rate of that progression are addressed within the framework of Systemic Functional Linguistics. Being largely qualitative, this study examines three consecutive textbooks issued by the Ministry of Education, which are available online for classroom use. Data were collected and sampled from the reading texts found in the textbooks and were analyzed with regard to lexical density, lexical variation and grammatical intricacy in order to find the complexity of the texts. The results of the analyses show that regardless of the inconsistent progression of text complexity within each textbook, there is a consistent pattern of text complexity progression across grade levels. In other words, the lexical density, lexical variation and grammatical intricacy across the textbooks were found to have consistent progression from one grade level to another of which the direction is positive. It could be concluded that in general the language used in the texts becomes increasingly sophisticated, especially at lexical level, in accordance with grade level progression to cater for students' intellectual development.
\end{abstract}

Keywords: SFL; text complexity; lexical density; lexical variation; grammatical intricacy; textbooks

For decades, textbooks have been considered to play a key role in the process of school education, determining what and how teachers teach (see e.g. Watts-Taffe, Gwinn, Johnson \& Horn, 2003; Dole \& Osborn, 2003; Reys, Reys \& Chávez, 2004; Apple, 1991; Elliot \& Woodwart, 1990). Palinscar and Duke (2004, p. 184) argue that even "when teachers elect not to teach from the text, texts play a significant role in determining the curriculum". The study by Radencich (1995) found that $95 \%$ of teachers' decisions are governed by the textbooks they use. Thus, students' success in school depends largely on their understanding of the texts, and this understanding is influenced "by a variety of features that characterize the nature of text" (Beck, McKeown \& Worthy, 1995, p. 220). Without close analysis of texts, it is hard to make conclusions about the efficiency of textbooks in the school instruction. As stated by Schleppegrell (2004, p. 2), “... a careful analysis of the linguistic challenges of learning is important for understanding the difficulties the students face and the limitations they demonstrate in talking and writing about topics they have studied."

The importance of exploring the language of textbooks has become more and more recognized. However, as Nathan, Long and Alibali (2002) argue, although textbooks are the main learning tool, "analyses of their composition and organization are often neglected in research on learning from text" (pp. 1-2). As teachers do not normally possess the linguistic knowledge necessary to realize the challenges the language can pose, they "need help to become aware of the language difficulties present in school textbooks" (Moss, 2006, p. 889).

There are several aspects of textbooks that are worth exploring such as their cultural, social, or textual elements. With regard to the textual elements, the text complexity of school textbooks, among other things, could be considered one key element in determining the students' success in grasping the ideas contained in the textbooks. By having an appropriate level of complexity, the texts will be comprehended well by the students and thus stimulate their development in learning both the subject and the language.

Text complexity is among the linguistic features of written texts that can affect the level of difficulty. Linguistic or text complexity is fundamental to the current science; however, its precise definition has still been an open issue (Kwapien, Drozdz \& Orczyk, 2010). In addition, while the notion of complexity is central to literacy and language education, there is no standard linguistic measure towards it (Rimmer, 2008). This study, therefore, focuses on the measurement of text 
complexity of English textbooks from three perspectives, i.e. lexical density, lexical variation, and grammatical intricacy.

Lexical density of texts is recognized as an important factor of complexity of written language (Halliday, 1989). Lexical density in this study is analyzed by applying the formula proposed by Halliday, which suggests that the number of lexical items per clause should be considered. The formula for Halliday's lexical density (LD) calculation is as follows (Castello, 2008, p. 97):

$$
\text { LD }(\text { index })=\frac{\text { Total number of lexical words }}{\text { Total number of ranking clauses }}
$$

Another important measurement of text complexity is lexical variation because, as Halliday (1989, p. 64) points out, "repetition reduces the effect of density". If there is an approximately equal number of grammatical and lexical items in two hypothetical texts, but in one text some lexical items are repeated several times, whereas in the other such items are used only once, then the second text is likely to be perceived as more difficult. The formula to calculate lexical variation $(\mathrm{LV})$ is as follows (Castello, 2008, p. 64):

$$
L V(\text { index })=\frac{\text { Number of different lexical words }}{\text { Total number of lexical words }}
$$

In order to get a better picture of text complexity, grammatical intricacy will also be measured. Grammatical intricacy refers to how often a clause complex appears in a text in comparison with simple clauses. Although grammatical intricacy tends to be used for the analysis of complexity of spoken language as argued by Halliday, it is worth including in the measurement of written text complexity since it can show the complexity not only at the level of words but also at the level of clauses. Grammatical intricacy (GI) is calculated using the following formula (Castello, 2008, p. 97):

$$
\text { GI (index) }=\frac{\text { Total number of ranking clauses }}{\text { Total number of clause complexes }}
$$

As for the complexity of texts, there have been a number of studies concerning vocabulary difficulty (lexical density and lexical variation of texts) such as those conducted by Gibson (1993), Ventola (1995), and readability such as those conducted by Bruce \& Rubin (1988) and Johnson (2000). Dale and Chall (1948) have developed a formula to measure the readability of school texts and rated texts used in U.S. schools to determine the reading level. Although this formula supposedly measures both lexical and syntactic complexity, its credibility was critiqued by some scholars on the assumption that there are many other factors that contribute to text difficulty (see e.g. Bruce \& Rubin, 1988; Gibson, 1993; Alderson, 2000). Indeed, the complexity of the text depends not only on the number of unfamiliar words but also on sentence length, lexical density, and lexical variation.

Previous linguistic research on text complexity in textbooks was influenced by Chomskyan formal linguistics (Chomsky, 1956), behaviorist theories of learning (Skinner, 1957), theories of cognitive development (Piaget, 1970), and sociolinguistic theories (Vygotsky, 1978). Since the 1980s, Systemic Functional Linguistics was "brought" to school textbooks first in Australia, then in other countries by Martin (2002), Eggins (2004), Schleppegrell (2004), Christie (2002), and many others. Their research on the language of schooling concentrated mainly on the language of math (Nathan, Long \& Alibali, 2002; Abel \& Exley, 2007), history (Moss, 2006; Martin, 2002; Schleppegrell \& Achugar, 2003; Coffin, 1997), and social sciences and natural sciences (Ninnes, 2001; Halliday \& Martin, 1993; Macken-Horarik, 2002).

The text complexity of textbooks of language learning has not been the primary focus of attention so far. Moreover, the texts on school textbooks have not been largely analyzed with regard to their complexity on the basis of Systemic Functional Linguistics, particularly in Indonesia. Therefore, this study is an attempt to analyze the text complexity of senior high school English textbooks based on the perspective of Systemic Functional Linguistics in the Indonesian context. Three senior high school textbooks written for different grades have been selected for a close analysis. Thus, sequence is important in this research (see Schleppegrell, 2004; Chall \& Squire, 1991). This research looks closely at the sequenced texts to see how text complexity progresses.

On the basis of the concerns mentioned above, the problems of the present study comprise (1) how lexical density progresses within and among the selected English textbooks, (2) how lexical variation progresses within and among the selected English textbooks, (3) how grammatical intricacy progresses within and among the selected English textbooks, and (4) the pedagogical implication that can be drawn from the exploration of text complexity of the textbooks for textbook writing and teaching purposes.

\section{METHOD}

The present study is mainly qualitative, supported by some descriptive quantification. The qualitative procedures were used to determine the category of lexical and functional words or items and to determine the category of ranking clauses in the texts. Meanwhile, the quantification was administered to find the indexes of lexical density, lexical variation and grammatical intricacy based on the formulas mentioned previously. All the analyses were drawn on a systemic functional perspective. 
This research focuses on the analysis of three sequential senior high school textbooks used in Indonesian schools. The data include the reading texts from those three textbooks. The textbooks selected for the study were issued by the Ministry of Education of the Republic of Indonesia in 2014 to be used as school textbooks in accordance with the latest curriculum, namely Curriculum 2013. These textbooks are available online in electronic book format (e-book) and can be downloaded freely for classroom use. They are a series of textbooks prepared by the same team of authors (Nurhasanah, Mahrukh Bashir, dan Sonya Sinyanyuri) published in 2004 by the Centre for Curriculum and Bookmaking, Ministry of Education of the Republic of Indonesia.

A total of nine texts were selected from the three different books and thus from three sequential grades with the following distribution: three texts from Grade 10 textbook (Textbook 1), three texts from grade 11 textbook (Textbook 2), and three texts from grade 12 textbook (Textbook 3). The three texts from each textbook were selected based on the chapters where the texts were situated. Three texts (Text 1 , Text 4 , and Text 7) were selected from the initial chapters of each textbook; another three texts (Text 2, Text 5, and Text 8) were selected from the middle chapters of each textbook; and the rest (Text 3, Text 6, and Text 9) were selected from the last chapters of each textbook. The selection was organized as such in order to investigate whether there is an increase of text complexity within and among textbooks.

The data obtained were analyzed in accordance with Systemic Functional Linguistics proposed by Halliday, which provides a powerful analytical tool and constitutes one of the linguistic approaches that have been well developed in the area of education (Freebody, 2003). The selected texts from the three textbooks were analyzed in terms of their complexity which covered the lexical density, lexical variation, and grammatical intricacy. The analyses of lexical density and grammatical intricacy were done manually. Meanwhile, the analysis of lexical variation involved an automation process by using AntConc 3.2.1w for Windows, a concordance program developed by Anthony (2007), to assist in identifying and calculating the lemmas (word families) that are present in the analyzed texts.

Basically, each of the reading texts was marked and tabulated for its lexical items (content words), grammatical items (function words), ranking clauses, and clause complexes. The content words or lexical items included verbs, nouns, adjectives, and adverbs. Determiners such as the, some, this, and each were regarded as nonadjectives. The phrasal verb was taken as one word or lexical item. The tense was also regarded as representing one verb. Furthermore, a clause was said to consist of one predicator, which was the basis for determining the grammatical intricacy.

\section{RESULTS AND DISCUSSION}

As stated earlier, the text complexity in this study has been examined through three different measures, those are lexical density, lexical variation and grammatical intricacy. Identification of elements that build the lexical density, lexical variation and grammatical intricacy were conducted qualitatively on the basis of the Systemic-Functional Linguistic concerns. The results of the analysis are presented as follows.

As discussed previously, lexical density contributes to the complexity of written texts in terms of the use of words. There are several methods for calculating lexical density of a text; however, this study uses the method proposed by Halliday. According to Halliday (1987), lexical density can be defined as the proportion of the lexical words or lexical items to the total number of words in the text. However, he further states that the number of lexical items per clause should be considered for the calculation rather than the total number of words. Therefore, the ratio of the lexical density in this study was calculated by dividing the number of lexical items with the number of ranking clauses in the text. The lexical items and the functional items as well as the ranking clauses were determined qualitatively on the basis of the theories presented earlier.

Table 1 shows that there are 556 lexical items in the first textbook, 1,091 lexical items in the second textbook, and 631 lexical items in the third textbook. Meanwhile, the number of ranking clauses in each textbook includes 215 clauses in the first textbook, 348 in the second textbook, and 181 in the third textbook. With these numbers, therefore, the lexical density of each textbook can be determined: 2.586 in the first textbook, 3.135 in the second textbook, and 3.486 in the third textbook. The results of the calculation are also presented in Figure 1 to show the direction of development of lexical density from one textbook to another.

Figure 1 shows an increase in lexical density index across textbooks. Textbook 1 has a lexical density index of 2.586, while Textbook 2 has a different lexical density index, that is 3.135 (.549 higher than the index of Textbook 1). Within the same direction, Textbook 3 has a lexical density index of 3.486. This index is .351 higher than that of Textbook 2. This result is in line with what To, Fan \&Thomas (2013) have found, i.e. an increase in the lexical density of the texts in accordance with the levels of the textbooks.

A high lexical density indicates a high number of lexical items in a clause. On the contrary, a low lexical density indicates a relatively low number of lexical items in a clause. In other words, the higher the lexical 
density index of a text is, the denser the information it provides, thus the more complex the text will be. Therefore, an increase in lexical density indexes of some sets of texts suggests an intensification of complexity among those sets of texts.

Table 1. Lexical density features across textbooks

\begin{tabular}{lrrr}
\hline \multirow{2}{*}{ Features } & \multicolumn{3}{c}{ Textbooks } \\
\cline { 2 - 4 } & $\mathbf{1}$ & $\mathbf{2}$ & $\mathbf{3}$ \\
\hline Words & 1,250 & 2,270 & 1,291 \\
\hline Grammatical items & 694 & 1,179 & 660 \\
\hline Lexical items & 556 & 1,091 & 631 \\
\hline Ranking clauses & 215 & 348 & 181 \\
\hline Halliday's Lexical Density (LDH) & 2.586 & 3.135 & 3.486 \\
\hline
\end{tabular}

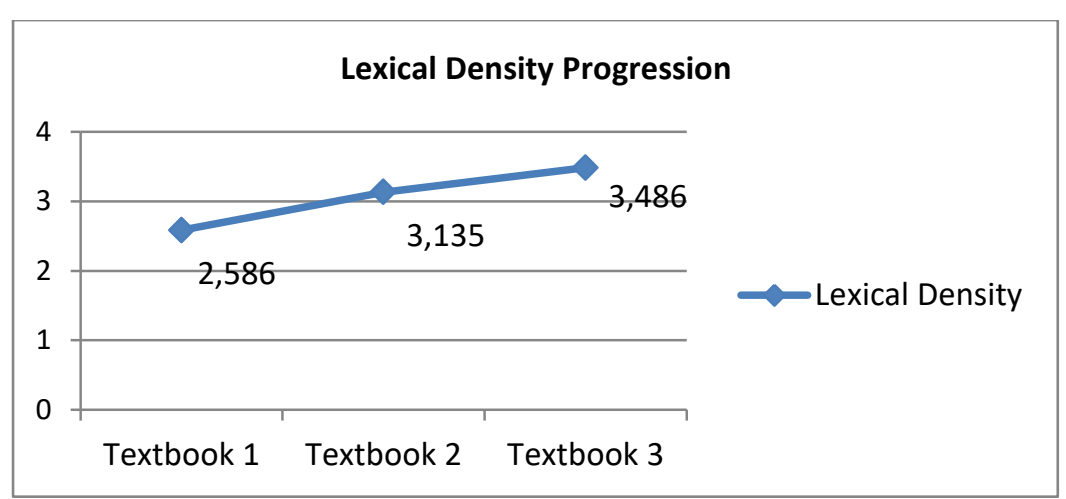

Figure 1. Lexical density progression across textbooks

As previously mentioned, the lexical density indexes of the reading texts in each textbook show an increase from one textbook to another and the direction of the increase is in accordance with the grades of the textbooks. It means that the higher the grade of a textbook is, the higher the lexical density index the textbook has. In other words, there is a development among those three textbooks in terms of their lexical density. Moreover, the number of lexical items, which carry the information in a text, also increases from one textbook to another. This phenomenon is in line with the academic expectation, i.e. that the higher the level of education is, the more complex and denser the knowledge that the students are expected to learn (for further explanation, see Bloom, Englehart, Furst, Hill \& Krathwohl, 1956).

In addition to lexical density, as mentioned previously, lexical variation is another important measure of text complexity. As stated by Halliday (1989), the repetition on a text creates the sense of reduction that affects the density or complexity of the text. It means that if there is an approximately equal number of grammatical and lexical items in two hypothetical texts, but in one text some lexical items are repeated several times, whereas in the other such items are used only once, then the second text is likely to be perceived as having more complexity or more difficult. Therefore it will be easier to understand the message contained in the first text than to understand that contained in the second. More variation in the use of the lexical items in a text results in more information to grasp by the readers at one time.
Table 2 shows that Textbook 1 has a lexical variation index of .572 , which is obtained by dividing the number of different lexical items or lemmas (318) with the number of lexical items (556). Meanwhile, Textbook 2, which has the number of word families (lemmas) of 560 and the number of lexical items of 1,091 , has a lexical variation index of .513 . Finally, Textbook 3, which has the number of word families of 451 and the number of lexical items of 631 , has a lexical variation index of .715. Figure 2 shows how lexical variation progresses from one textbook to another.

Figure 2 shows an up-and-down progression in lexical variation index from one textbook to another. Textbook 1 has an index of lexical variation of .572, while Textbook 2 has a slightly different lexical variation index, that is .513 , which is .059 lower than the index of Textbook 1. A different trend can be noted with regard to Textbook 3, which has a lexical variation index of .715. This index is .202 higher than the index of lexical variation of Textbook 2 and .143 higher than that of Textbook 1 .

A high lexical variation indicates a highly varied use of lexical items in one clause. On the contrary, a low lexical variation indicates a relatively low variation in the use of lexical items in a clause. In other words, the higher the lexical variation index of a text is, the more information there is to be comprehended at one time in the text, thus the more complex the text will be. Therefore, an increase in lexical variation indexes of some sets of texts suggests an intensification of complexity among those sets of texts. 
Table 2. Lexical variation features across textbooks

\begin{tabular}{lrrc}
\hline \multirow{2}{*}{ Features } & \multicolumn{3}{c}{ Textbooks } \\
\cline { 2 - 4 } & $\mathbf{1}$ & $\mathbf{2}$ & $\mathbf{3}$ \\
\hline Grammatical items & 694 & 1,179 & 660 \\
\hline Lexical items & 556 & 1,091 & 631 \\
\hline Lemmas (word families) & 318 & 560 & 451 \\
\hline Halliday's Lexical Variation (LV) & .572 & .513 & .715 \\
\hline
\end{tabular}

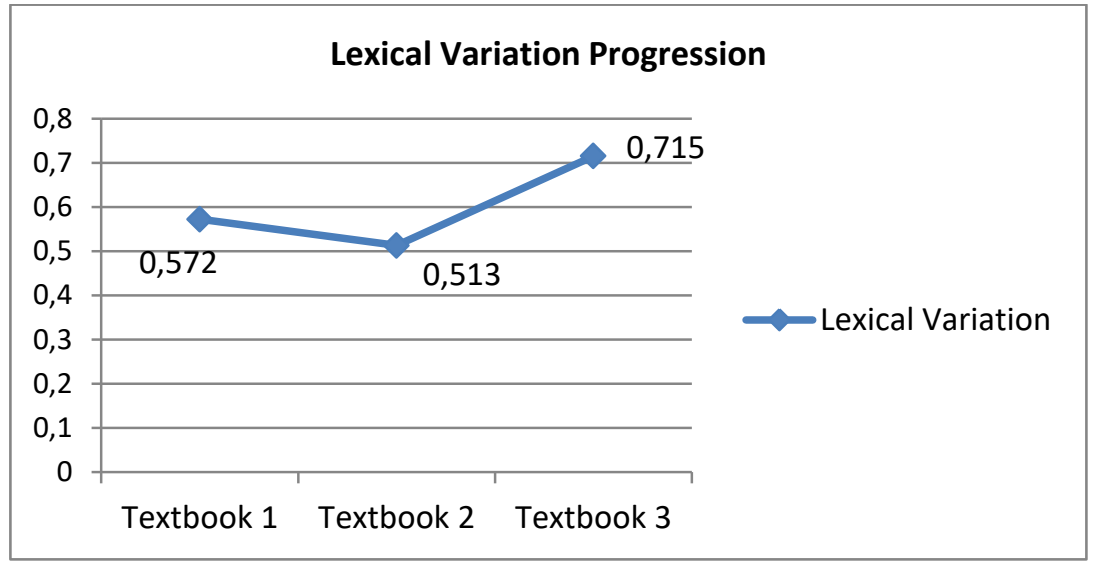

Figure 2. Lexical variation progression across textbooks

Despite the up-and-down progression of lexical variation from one textbook to another, the general trend is that the progression is increasing because the index of Textbook 3 is higher than those of Textbooks 1 and 2 . In other words, the direction of the progression tends to be in line with the grades or levels of the textbooks. It means that the higher the grade of the textbook is, the higher the lexical variation index the textbook has. Moreover, the use of lexical items, which carry the information in a text, also becomes richer, in this case more varied, from one textbook to another. This phenomenon is in general in line with that of lexical density, and this supports what has been proposed in Bloom's taxonomy that has become the worldwide academic or educational expectation.

As stated in the previous analysis of lexical density, the phenomenon of increasing lexical variation from one textbook to another in accordance with the grades of the textbooks could have a positive effect on the way the students learn English. Moreover, packaging the textbooks in such a way that the lexical variation is set to increase from one grade to another will provide students with opportunities to cope with texts that have denser and richer information, which in turn directs them to improve their understanding of higher level academic texts, the type of texts that is more likely to be run into by the students in higher levels of education and academic life.

The last measurement of text complexity in this study is grammatical intricacy. As has been elaborated previously, grammatical intricacy concerns text complexity with regard to the occurrences of clauses and clause complexes in a text. Halliday and Matthiessen (2004) state that the complexity of a text can also be examined through the intricacy of the grammatical representation in that text. The grammatical intricacy of the texts under focus is summarized in Table 3.

Table 3 shows that the total number of clauses in texts taken from Textbook 1 is 215 . Meanwhile, Textbook 2 and Textbook 3 have the total number of clauses of 348 and 181 respectively. Furthermore, Textbook 1 contains 178 clauses in 73 clause complexes, while Textbook 2 contains 318 clauses in 109 clause complexes and Textbook 3 has 158 clauses in 51 clause complexes. On the basis of those numbers, the grammatical intricacy of each textbook can be calculated and compared to identify the progression of grammatical intricacy levels across textbooks. The results of the calculation of grammatical intricacy of each textbook are as follows: GI of Textbook 3 (3.098) is higher than GI of Textbook 2 (2.917), which is in turn higher than GI of Textbook 1 (2.438). This progression in grammatical intricacy is graphically represented in Figure 3.

As shown in Figure 3, there is an increase of grammatical intricacy from the first to the last textbooks. The highest grade textbook, which is Textbook 3, has the highest level of grammatical intricacy, i.e. 3.098. This is slightly higher than the grammatical intricacy of Textbook 2 (2.917), which is .181 lower than that of Textbook 3. The least grammatically intricate among those three textbooks is Textbook 1, which has the grammatical intricacy level of 2.438. This figure is .479 lower than that of Textbook 2, and .66 lower than that of Textbook 3 .

A high grammatical intricacy index indicates a relatively high number of clauses that are combined in clause complexes. In contrast, a low grammatical intricacy index indicates a relatively low number of clauses that are combined in clause complexes. In 
other words, the higher the grammatical intricacy of a text is, the more intricate or complex the clause representation of that text will be. As mentioned previously, the grammatical intricacy of the texts in each textbook shows an increase from one textbook to another and the direction of the increase is consistent with the grades of the textbooks. It means that the higher the grade of the textbook is, the higher the grammatical intricacy level the textbook has. In other words, there is a development among those three textbooks in terms of their grammatical intricacy.

It should be noted, however, that while increases in lexical density and lexical variation tend to result in higher abstraction requiring more cognitive efforts to discern the text, an increase in grammatical intricacy tends to result in lower abstraction because ideas are segmented into chunks more extensively so that nominalisations tend to be deconstructed into processes. These contradictory findings need further explanation in the context of the promotion of higher level of thinking through abstraction.

One possible explanation is that the textbook writers are not aware of the effect of lexical density, lexical variation, and grammatical intricacy on a text, i.e that the first two promotes abstraction while the last lessens it. Another possible explanation is that the writers are aware of this concern, but they deliberately combine the characteristics of lexical density, lexical variation, and grammatical intricacy to facilitate comprehension. In other words, abstraction is promoted through lexical density and lexical variation, while at the same time abstraction is lessened through grammatical intricacy (see Fang, 2005). This means that the effect of the increasing information density is lessened by the effect of the increasing grammatical intricacy.

The academic expectation is that students encounter new knowledge through language as their level of education progresses. The texts of advanced literacy that are characterized with density and abstractness of language are meant to represent the specialization and abstraction of the knowledge that students are projected to cultivate as they progress into higher level of education (see Bloom et al., 1956; Schleppegrell, 2004). It appears that in terms of lexical density and lexical variation the textbooks support this concern, while the grammatical intricacy to some extent lessens the effect of the lexical complexity.

Table 3. Grammatical intricacy features across textbooks

\begin{tabular}{lrrr}
\hline \multirow{2}{*}{ Features } & \multicolumn{3}{c}{ Textbooks } \\
\cline { 2 - 4 } & $\mathbf{1}$ & $\mathbf{2}$ & \multicolumn{1}{c}{$\mathbf{3}$} \\
\hline Clauses & 215 & 348 & 181 \\
\hline Clause simplexes & 37 & 30 & 23 \\
\hline Clause complexes & 73 & 109 & 51 \\
\hline Clauses in clause complexes & 178 & 318 & 158 \\
\hline Grammatical intricacy $(\mathrm{GI})$ & 2.438 & 2.917 & 3.098 \\
\hline
\end{tabular}

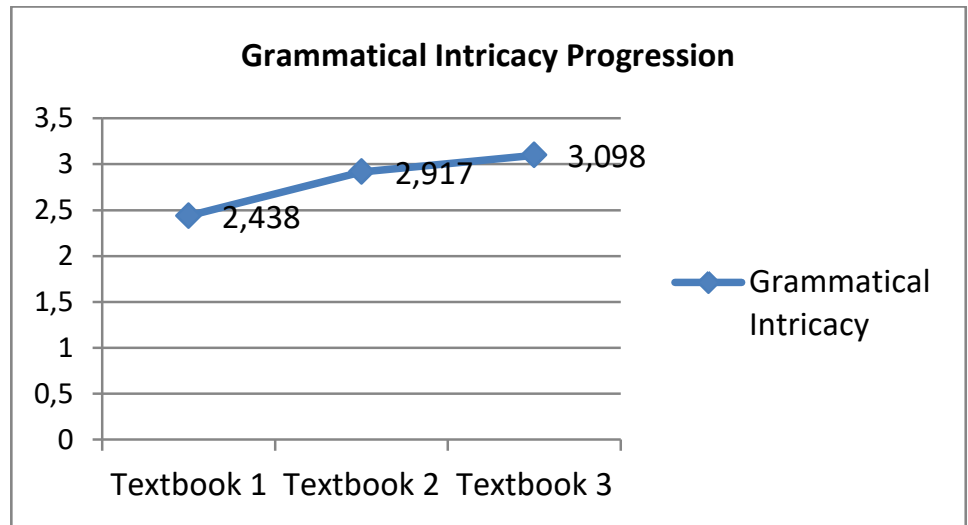

Figure 3. Grammatical intricacy progression across textbooks

\section{CONCLUSION}

This study is an attempt to analyze the text complexity of senior high school English textbooks from the perspective of Systemic Functional Linguistics in the Indonesian context. The text complexity in this study concerns lexical density, lexical variation, and grammatical intricacy. Accordingly, four research problems are formulated, i.e. (1) how lexical density develops within and among the selected English textbooks, (2) how lexical variation develops within and among the selected English textbooks, (3) how grammatical intricacy develops within and among the selected English textbooks, and (4) what pedagogical implication can be drawn from the exploration of text complexity of the textbooks.

This study is conducted largely through qualitative design. Three English textbooks for 
senior high school students were selected for a close analysis. The reading text sections of the three consecutive English textbooks were chosen as the focus of the study, and the texts were analyzed for their lexical density, lexical variation, and grammatical intricacy. Analytical tools developed in Systemic Functional Linguistics were employed for the analysis.

The results of this study show that the lexical density indexes among the three textbooks increase from the lower to the higher grades. In other words, the lexical density becomes increasingly higher in accordance with the grades. Therefore, the textbooks become lexically denser and thus more complex across grades. Meanwhile, the lexical density indexes within each textbook do not always have a consistent pattern of progression. In other words, the lexical density of the texts in the final chapters of the textbooks is not always higher than the lexical density of the texts in the initial and middle chapters. This may result from the different genres and topics discussed in those chapters.

It is also found that the lexical variation indexes among the three textbooks have a tendency to increase from the lower to the higher grades. The only exception is Textbook 2, which has a lower lexical variation index than that of Textbook 1 . However, in general the lexical variation across the textbooks can still be considered to be increasing since the last textbook has the highest index among those three textbooks. It can therefore be concluded that the textbooks become more varied in terms of the use of lexical items in accordance with the grades of the textbooks. In short, the higher the level of the textbook is, the more varied the lexical words in the textbook are. Meanwhile, like the lexical density indexes within each textbook, the lexical variation indexes of the texts within each textbook do not always have a consistent pattern. This may also result from the different genres and topics discussed in those chapters.

With regard to grammatical intricacy, it is found that the grammatical intricacy indexes across the three textbooks increase from the lower to the higher grades. In other words, the grammatical intricacy becomes higher from one textbook to another in accordance with the grades. In short, the higher the level of the textbook is, the more intricate the grammatical structure of the texts in the textbook is. Meanwhile, the grammatical intricacy indexes within each textbook do not always have a consistent pattern of progression, which is similar to the phenomenon found in lexical density and lexical variation. This also seems to result from the different topics and genres discussed in those chapters.

The increase in lexical density and lexical variation across grades tends to result in higher abstraction; however, the increase in grammatical intricacy tends to result in lower abstraction. It is possible that the textbook writers are not aware of the effect of lexical density, lexical variation, and grammatical intricacy on a text, i.e that the first two promotes abstraction while the last lessens it. Another possible explanation is that the writers deliberately promote abstraction through lexical density and lexical variation, while at the same time lessen it through grammatical intricacy. In other words, the effect of the increasing information density is lessened by the effect of the increasing grammatical intricacy. The increase in complexity due to the increase in lexical density and lexical variation from one grade to another is in line with the academic expectation that the language used in the textbooks becomes gradually more complex and more abstract to promote higher order thinking.

Exploring the language used in pedagogical practices such as textbooks is beneficial to textbook writers. They are expected to rely not only on their intuition in composing texts but also on a sufficient analysis of the language in order to facilitate students' intellectual development. Awareness of the effect of text complexity on comprehension will hopefully result in better texts for pedagogical purposes. Texbook writers can carefully prepare texts with proper complexity progression both within and across textbooks. Furthermore, exploration of the lexicogrammatical features of the language, including text complexity, used in textbooks will also be helpful for teachers. With this knowledge in mind, teachers are expected to use textbooks with more confidence, knowing possible pitfalls and challenges that the language of instruction poses.

\section{ACKNOWLEDGMENT}

Universitas Pendidikan Indonesia, particularly Department of English Education, is gratefully acknowledged for supporting the research.

\section{REFERENCES}

Abel, K. \& Exley, B. (2007). Using Halliday's functional grammar to examine early years worded mathematics texts. In A. McNamara, J. Rickwood, R. van Haren \& J. Vereoorn (Eds.), Proceedings of Critical Capital: Teaching \& Learning AATE \& ALEA National Conference (pp. 1-12). Canberra: Australian National University.

Alderson, J.C. (2000). Assessing reading. Cambridge: Cambridge University Press.

Anthony, L. (2007). AntConc (3.2.1w) [Computer Software]. Tokyo: Waseda University. Available from http://www.antlab.sci.waseda.ac.jp/

Apple, M. (1991). The culture and commerce of the textbook. In M. Apple and L. Christian-Smith (Eds.), The politics of the textbook (pp. 147162). New York: Routledge. 
Beck, I.L., McKeown, M.G. \& Worthy, J. (1995). Giving a text voice can improve students' understanding. Reading Research Quarterly, 20(2), 220-238.

Bloom, B., Englehart, M. Furst, E., Hill, W. \& Krathwohl, D. (1956). Taxonomy of educational objectives: The classification of educational goals. Handbook I: The cognitive domain. New York: David McKay Co Inc.

Bruce, B. \& Rubin, A. (1988). Readability Formulas: Matching Tool and Task. In A. Davison and G. M. Green (eds). Linguistic Complexity and Text Comprehension. New Jersey: Lawrence Erlbaum Associates, Publishers, 5-22.

Castello, E. (2008). Text complexity and reading comprehension tests. Bern: International Academic Publishers.

Chall, J. \& Squire, J.R. (1991). The publishing industry and textbooks. In R. Barr, M. L. Kamil, P. B. Mosenthal \& P. D. Pearson (Eds), Handbook of reading research (pp. 120-146). New York: Longman.

Chomsky, N. (1956). Three models for the description of language. IRE Trans.on Inform. Theory IT-2, No. 3, 113-124.

Christie, F. (2002). Classroom discourse analysis: A functional perspective (Open Linguistics series. Ed. R. Fawcett). London: Continuum.

Coffin, C. (1997). Constructing and giving value to the past: an investigation into secondary school history. In F. Christie \& J. R. Martin (Eds.), Genre and institutions: Social processes in the workplace and school (pp. 196-230). London: Cassell.

Dale, E. \& Chall, J.S. (1948). A formula for predicting readability. Educational Research Bulletin, 27, 37-54.

Dole, J.A. \& Osborn, J. (2003). Elementary language arts textbooks: A decade of change. In J. Flood, D. Lapp \& J. R. Squire (Eds.), Handbook for research on teaching the English Language Arts (pp. 631-639). New York: Macmillian.

Eggins, S. (2004). An introduction to systemic functional linguistics (2nd Ed.). New York: Continuum.

Elliot, D. \& Woodward, A. (Eds.). (1990). Textbooks and schooling in the United States (90th yearbook of the society for the study of education). Chicago: University of Chicago Press.

Fang, Z. (2005). Scientific literacy: A systemic functional linguistics perspective. Science education, 89(2), 335-347.

Freebody, P. (2003). Qualitative research in education: Interaction and practice. London: Sage.
Gibson, T.R. (1993). Towards a discourse theory of abstracts and abstracting. Nottingham: University of Nottingham.

Halliday, M.A.K. (1987). Spoken and written modes of meanings. In R. Horowitz and S. J. Samuels (Eds), Comprehending Oral and Written Language (pp. 55-82). San Diego: Academic Press.

Halliday, M.A.K. (1989). Spoken and written language. Oxford: Oxford University Press.

Halliday, M.A.K. \& Martin, J.R. (1993). Writing science: Literacy and discursive power. London: University of Pittsburgh Press.

Halliday, M.A.K. \& Matthiessen, C. (2004). An introduction to functional grammar $\left(3^{\mathrm{rd}} \mathrm{Ed}.\right)$. London: Arnold.

Johnson, K. (2000). Readability. Retrieved on October $10^{\text {th }}, 2014$ from http://www.timetabler.com/reading.html

Kwapien, J.J., Drozdz, S.S. \& Orczyk, A.A. (2010). Linguistic complexity: English vs. Polish, text vs. corpus. Acta Physica Polonica, A., 117(4), 716-720.

Macken-Horarik, M. (2002). 'Something to shoot for': A systemic functional approach to teaching genre in secondary school science. In A. M. Johns (Ed.), Genre in the classroom (pp. 21-46). Mahwah, NJ: Erlbaum.

Martin, J.R. (2002). Meaning beyond the clause: SFL perspectives. Annual Review of Applied Linguistics, 22, 52-74.

Moss, G. (2006). Textbook language, teacher mediation, classroom interaction and learning processes: The case of natural and social science textbooks in Barranquilla, Colombia. In B. Leila \& T. B. Sardinha (Eds.) Proceedings of 33rd International Systemic Functional Congress (pp. 879-894). San Paulo: PUCSP.

Nathan, M.J., Long, S.D. \& Alibali, M.W. (2002). The symbol precedence view of mathematical development: A corpus analysis of the rhetorical structure of textbooks. Discourse Processes, 33(1), 1-21.

Ninnes, P. (2001). Representations of ways of knowing in junior high school science texts used in Australia. Discourse: Studies in the Cultural Politics of Education, 22(1), 81-94.

Palinscar, A.S. \& Duke, N.C. (2004). The role of text and text/reader interactions in young children's reading development and achievement. Elementary School Journal, 105(2), 183-198.

Piaget, J. (1970). Science of education and the psychology of the child. (D. Coltman, Trans.). New York : Orion Press.

Radencich, M.C. (1995). Administration \& supervision of the reading/writing program. Needham Heights, MA: Allyn \& Bacon. 
Reys, B.J., Reys, R.E. \& Chávez, O. (2004). Why mathematics textbooks matter. Educational Leadership, 61(5), 61-66.

Rimmer, W. (2008). Putting grammatical complexity in context. Literacy, 42(1), 29-35. doi: 10.1111/j.1467-9345.2008.00478.x.

Schleppegrell, M.J. (2004). The Language of schooling: A functional linguistic perspective. Mahwah: Lawrence Erlbaum Associates.

Schleppegrell, M.J. \& Achugar, M. (2003). Learning language and learning history: A functional linguistics approach. TESOL Journal, 12(2), 21-27.

Skinner, B.F. (1957). Verbal behavior. Englewood Cliffs, NJ: Prentice-Hall.

To, V., Fan, S. \& Thomas, D.P. (2013). Lexical density and readability: A case study of
English textbooks. The International Journal of Language, Society and Culture, 37(7), 6171.

Ventola, E. (1995). Thematic Development and Translation. In M. Ghadessy, Thematic Development in English Text (pp. 85-104). London: Pinter.

Vygotsky, L. (1978). Interaction between learning and development. From: Mind and Society (pp. 79-91). Cambridge: Harvard University Press.

Watts-Taffe, S., Gwinn, C.B., Johnson, J.B. \& Horn, M.L. (2003). Preparing pre-service teachers to integrate technology with the elementary literacy program. The Reading Teacher, 57 (2), 130-138. 